\title{
Electromagnetic Fields Effects on the Secondary Structure of Lysozyme and Bioprotective Effectiveness of Trehalose
}

\author{
Emanuele Calabrò and Salvatore Magazù \\ Department of Physics, University of Messina, Street D'Alcontres 31, 98166 Messina, Italy \\ Correspondence should be addressed to Emanuele Calabrò, e.calabro@yahoo.com
}

Received 8 April 2012; Revised 1 July 2012; Accepted 23 July 2012

Academic Editor: Sergei Tretiak

Copyright () 2012 E. Calabrò and S. Magazù. This is an open access article distributed under the Creative Commons Attribution License, which permits unrestricted use, distribution, and reproduction in any medium, provided the original work is properly cited.

\begin{abstract}
FTIR spectroscopy was used to investigate the effects of extremely low frequency $(50 \mathrm{~Hz})$ electromagnetic field and of microwaves at $900 \mathrm{MHz}$ on the secondary structure of a typical protein, the lysozyme, evaluating the bioprotective effectiveness of trehalose. Lysozyme in $\mathrm{D}_{2} \mathrm{O}$ solution $(60 \mathrm{mg} / \mathrm{mL})$ was exposed to $50 \mathrm{~Hz}$ frequency electromagnetic field at $180 \mu \mathrm{T}$. The FTIR spectra indicated an increase of $\mathrm{CH}_{2}$ group at 1921 and $1853 \mathrm{~cm}^{-1}$ after $3 \mathrm{~h}$ of exposure. Such effect was not observed after the addition of trehalose $(150 \mathrm{mg} / \mathrm{mL})$ at the same exposure conditions. Lysozyme dissolved in $\mathrm{D}_{2} \mathrm{O}$ at the concentration of $100 \mathrm{mg} / \mathrm{mL}$ was exposed up to $4 \mathrm{~h}$ to $900 \mathrm{MHz}$ mobile phone microwaves at $25 \mathrm{~mA} / \mathrm{m}$. A significant increase in intensity of the amide I vibration band in the secondary structure of the protein was observed after $4 \mathrm{~h}$ exposure to microwaves. This effect was inhibited by the presence of trehalose at the concentration of $150 \mathrm{mg} / \mathrm{ml}$. Fourier self-deconvolution spectral analysis of lysozyme in $\mathrm{D}_{2} \mathrm{O}$ solution after exposure to microwaves revealed an increase in intensity of the conformational components of amide I mode, particularly of $\beta$-sheet and turn that can be attributed to disorder and unfolding processes of the protein.
\end{abstract}

\section{Introduction}

The aim of this work is to investigate the effects of the environmental electromagnetic fields on the secondary structure of hydrated lysozyme in absence and in the presence of the disaccharide trehalose.

Proteins are fundamentals in organic metabolism of livings. In the cells each protein must fold into the specific conformational state in a complex and highly crowded environment, and the folding process is aided by a range of auxiliary proteins $[1,2]$.

Lysozyme (LYS) is a residue protein found in secretions (e.g., saliva, sweat, and mucus) and more generally in leukocytes and kidneys.

Epidemiological studies carried out up to now evidenced a relationship between an increase of risk of cancer and the exposure to extremely low frequency electromagnetic field (ELF-EMF) [3] and to radiofrequencies and microwaves (RF-MWs) [4].
In response to public concern over health effects of EMF exposure, in 1996, the International EMF Project was established by WHO and the Radiation and Environmental Health Unit, which coordinated studies on EMF relative to the Environmental Health Criteria (EHC), whose main objective was to review the scientific literature on the biological effects of exposure to ELF-EMF fields to assess any health risks from exposure to these fields. In particular, the International Agency for Research on Cancer (IARC) concluded that ELFEMFs are possibly carcinogenic to humans [5].

Fourier transform infrared spectroscopy (FTIR) was used to study the effects of exposure to ELF-EMFs on the secondary structure of haemoglobin to ELF-EMF [6].

In fact, FTIR can be considered as a valuable tool for analyzing protein structure in $\mathrm{H}_{2} \mathrm{O}$-based structure or in deuterated form, as IR spectroscopy detects transitions between rotational and vibration energy levels, yielding much more information on molecular structure $[7,8]$. 
Otherwise, it was largely demonstrated that several types of environmental stress agents can alter the secondary structure of proteins.

Furthermore, several experimental studies have indicated that mobile phone radiation is not physiologically inert.

Mobile phone MWs have effects on blood-brain barrier permeability $[9,10]$ and can produce oxidative damage in brains tissues [11].

Significant concern has been raised about the capacity of MW radiations to change heat shock proteins levels [12] and to induce significant changes in the secondary structure of proteins [13].

Several researches carried out up to now on protein thermal denaturations confirmed a bioprotection mechanism by disaccharides $[14,15]$. In particular, investigations carried out on lysozyme thermal denaturations evidenced a mechanism of bioprotection by disaccharides. It was proved by studies on lysozyme that trehalose was the most efficient bioprotectant to preserve the native conformation of the protein against high temperatures [16]. Several hypotheses have been proposed to explain why trehalose is particularly effective. Crowe et al. [17] formulated the so-called "water replacement hypothesis," for which a direct trehalosebiostructures interactions occurs.

Cryptobiosis, from Greek kryptos, which means both "hidden" and "coated", refers to a particular state of organisms, during which undetectable hidden levels of metabolic functions are maintained for mending prohibitive environmental conditions. Further results evidenced that the structural properties of water are locally perturbed more strongly by trehalose in respect to sucrose and maltose $[18,19]$. Other experiments on trehalose $/ \mathrm{H}_{2} \mathrm{O}$, maltose $/ \mathrm{H}_{2} \mathrm{O}$, and sucrose $/ \mathrm{H}_{2} \mathrm{O}$ mixtures, through the intensity profile of the bending modes identified by a density functional simulation, appear more structured, indicating that trehalose forms with water molecules entities which show a more "cryptocrystalline" behaviour: the macroscopically glassy protective shell hides a local crystalline character [20-23].

In this work the effects of ELF-EMF and MWs on lysozyme in absence and in presence of trehalose were studied using FTIR spectroscopy to analyze vibration bands of protein linkages in the midinfrared region.

\section{Materials and Methods}

Lysozyme was purchased from Sigma-Aldrich (Milan, IT). Prior to infrared spectroscopy, the protein was dissolved in $\mathrm{D}_{2} \mathrm{O}$ at $20^{\circ} \mathrm{C}$ at the concentrations of $60 \mathrm{mg} / \mathrm{mL}$ and $100 \mathrm{mg} / \mathrm{mL}$.

The exposure system for the first part of the experiment consisted of a couple of Helmholtz coils linked to an AC voltage regulating up to 230 volt, at the frequency of $50 \mathrm{~Hz}$. It was used to generate time-varying extremely low electromagnetic fields. This device was used to expose samples at a magnetic flux density whose intensity was fixed at $180 \mu \mathrm{T}$. The magnetic field was continuously monitored by a magnetic field probe GM07 Gmeter of HIRST Magnetic Instruments Ltd., UK.
Lysozyme was prepared in $\mathrm{D}_{2} \mathrm{O}$ solution $60 \mathrm{mg} / \mathrm{mL}$ for control and exposed samples. Analogue samples were added with trehalose $150 \mathrm{mg} / \mathrm{mL}$. The samples were placed at the centre of the uniform field area between the coils. Either exposed or control samples were located in the same room at a temperature of $20^{\circ} \mathrm{C}$.

The second exposure system consisted of an operational mobile phone Samsung model SGH-C140 by which the microwaves were transmitted. The signal provider was Vodafone.

Samples of $250 \mu \mathrm{L}$ of lysozyme in $\mathrm{D}_{2} \mathrm{O}$ solution at the concentration of $100 \mathrm{mg} / \mathrm{mL}$ were placed at three centimeters from the mobile phone and exposed to the relative GSM $900 \mathrm{MHz}$ microwaves. Analogue samples added with trehalose $150 \mathrm{mg} / \mathrm{mL}$ were exposed to the same MWs source.

The average intensity of the magnetic component was $25 \mathrm{~mA} / \mathrm{m}$ and was measured during exposure by an SRM3000 instrument of Narda Safety Test Solutions. The device was linked through a cable to a Narda three axis antenna covering the frequency range from $75 \mathrm{MHz}$ to $3 \mathrm{GHz}$. The spectrum Analysis mode of the device was chosen as preliminary analysis to detect the MWs frequencies values impinging the three axis antenna. Better results were obtained by a resolution bandwidth $\mathrm{RBW}=6 \mathrm{MHz}$ and the average mode of the measured values were taken over a number of 16 results. The intensities of the power density and magnetic components of MWs were continuously monitored using time analysis mode.

Spectrum and time analyses results were transferred to a PC where the electromagnetic components related to MWs emitted by the mobile phone were monitored during exposure. Not exposed samples were placed in the same room at the temperature of $20^{\circ} \mathrm{C}$.

FTIR absorption spectra were recorded by a spectrometer Vertex $80 \mathrm{v}$ of Bruker Optics.

Lysozyme solution samples, in the absence or presence of sucrose and trehalose, were placed between a pair of $\mathrm{CaF}_{2}$ windows separated with a $25 \mu \mathrm{m}$ Teflon spacer.

Absorbance method was chosen for spectrum collection. For each spectrum 64 interferograms were collected and coadded by Fourier transformed employing a Happ-Genzel apodization function to generate a spectrum with a spectral resolution of $4 \mathrm{~cm}^{-1}$. IR spectra of $\mathrm{D}_{2} \mathrm{O}$ solution were subtracted from the spectra at the corresponding temperature. Each measure was performed under vacuum to eliminated minor spectral contributions due to residual water vapor. However, a smoothing correction for atmospheric water background was performed. IR spectra were baseline corrected and area normalized.

In particular, vector normalization was used, calculating the average value of the spectrum and subtracting from the spectrum decreasing the midspectrum. The sum of the squares of all values was calculated, and the spectrum was divided by the square root of this sum. The automatic baseline scattering correction function was used to subtract baselines from spectra, which allows getting spectra with band edges of up to the theoretical baseline.

In addition, second-derivative analysis of infrared spectra was performed to enhance the fine spectral structure, 
approximating the intrinsic shape of an infrared absorbance by a Lorentzian function [8], in which the peak frequency is practically identical with the original peak frequency, but the half bandwidth is reduced.

\section{Results and Discussion}

The effects of exposure of lysozyme in $\mathrm{D}_{2} \mathrm{O}$ solution (in absence and in presence of trehalose) to a low frequency $(50 \mathrm{~Hz})$ electromagnetic field were investigated analyzing vibration bands of protein linkages in the mid-infrared spectroscopy region. FTIR can be considered as a valuable tool for analyzing protein structure in $\mathrm{H}_{2} \mathrm{O}$-based structure or in deuterated form $[7,8,24]$. In fact, unlike UV-VIS spectroscopy which probes transitions between electronic states, IR spectroscopy detects transitions between rotational or vibration energy levels, yielding much more information on molecular structure. The most intense band of the spectrum of protein secondary structure is the amide I band around $1650 \mathrm{~cm}^{-1}$, that arises mainly from the $\mathrm{C}=\mathrm{O}$ stretching vibration with minor contributions of the $\mathrm{C}-\mathrm{N}$ stretching vibration and the $\mathrm{N}-\mathrm{H}$ in-plane bend. The band shape of the amide I mode can be considered as overlapping bands representing $\alpha$-helices, $\beta$-sheets, turns and random structures. The weak intense band around $1550 \mathrm{~cm}^{-1}$ is the amide II band. It mainly corresponds to a mixture of $\mathrm{N}-$ $\mathrm{H}$ in-plane bend and $\mathrm{C}-\mathrm{N}$ stretch. The secondary structure of lysozyme is characterized by $\alpha$-helices (41\%) and $\beta$-sheets $(21 \%)[25,26]$. Lysozyme was prepared in $\mathrm{D}_{2} \mathrm{O}$ because there is no vibrational contribution of $\mathrm{D}_{2} \mathrm{O}$ to the spectrum of the protein in the amide I region, while FTIR spectrum of $\mathrm{H}_{2} \mathrm{O}$ is characterized by a broad band around $1630 \mathrm{~cm}^{-1}$ corresponding to the bending vibration of the molecule. The FTIR spectrum was analyzed for monitoring changes of the secondary structure of lysozyme due to ELF-EMF exposure. After three hours of exposure at the intensity of $180 \mu \mathrm{T}$ no appreciable alterations were detected in the amide I and II regions. In contrast, relevant changes were observed after exposure in the range from 2800 to $3000 \mathrm{~cm}^{-1}$, as shown in Figure 1. In this region symmetric and asymmetric $\mathrm{CH}_{2}$ and $\mathrm{CH}_{3}$ stretching vibrations of protein side chains are generally observed, assigned to methylene and methyl group. In particular, the bands close to 2960 and $2870 \mathrm{~cm}^{-1}$ originate, respectively, from the asymmetric stretching $v_{\mathrm{as}} \mathrm{CH}_{3}$ and the symmetric stretching $v_{s} \mathrm{CH}_{3}$ of $\mathrm{CH}_{3}$ methyl groups, whereas vibration bands around 2921 and $2853 \mathrm{~cm}^{-1}$ are assigned to symmetric and asymmetric bending $v_{s} \mathrm{CH}_{2} v_{\text {as }} \mathrm{CH}_{2}$, respectively $[27,28]$. The intensity of both bands of methylene group was observed to increase after the exposure to the electromagnetic field, as can be observed in Figure 1. Applying a statistical analysis ( $t$ test) to the integrated area of $v_{s} \mathrm{CH}_{2}$ stretching vibration bands of different spectra, we found that their increase after exposure was significantly different in comparison to controls $(P<0.01)$.

This effect was observed during exposure of human neuronal-like cells to static and $50 \mathrm{~Hz}$ electromagnetic fields at the intensities of $2 \mathrm{mT}$ and $1 \mathrm{mT}$, respectively [29].

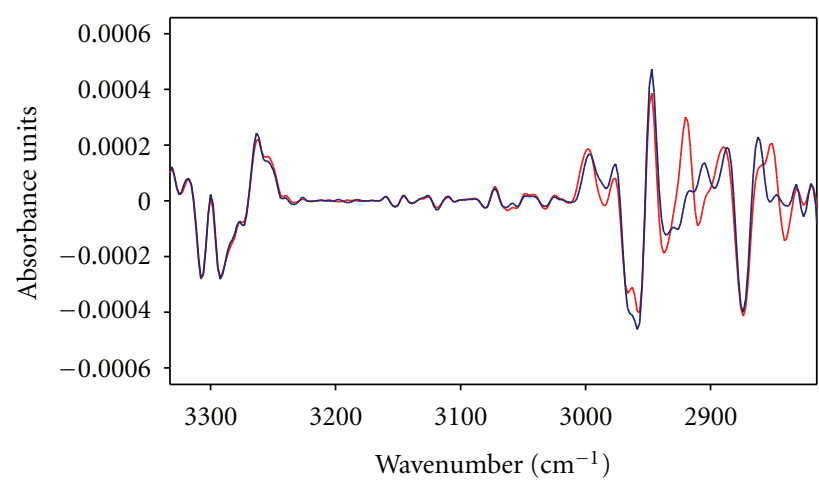

FIgURE 1: Acquired spectra in mid-infrared region from 3400 to $2800 \mathrm{~cm}^{-1}$ of lysozyme in $\mathrm{D}_{2} \mathrm{O}$ solution. Red line represents the exposed sample spectrum, after $3 \mathrm{~h}$ of exposure to a magnetic field of $180 \mu \mathrm{T}$. The increases of $\mathrm{CH}_{2}$ bands at 2921 and $2853 \mathrm{~cm}^{-1}$ for exposed sample can be observed.

In order to enhance the fine spectral structures in this spectral region, second-derivative analysis of lysozyme infrared spectra was performed. In the second-derivative spectrum, the intrinsic shape of an infrared absorbance is approximated by a Lorentzian function [8], and the peak frequency is practically identical with the original peak frequency; but the half-bandwidth is reduced. Secondderivative spectrum analysis confirmed the increase of the intensity of $v_{s} \mathrm{CH}_{2}$ and $v_{\text {as }} \mathrm{CH}_{2}$, as represented in Figure 2(a). The addition of trehalose reduced drastically these effects due to the exposure to electromagnetic field. Spectra of lysozyme in trehalose $\mathrm{D}_{2} \mathrm{O}$ solution were acquired after analogue exposure time. Second-derivative analysis was carried out to enhance the fine spectral structure in that spectral region, not evidencing any appreciable change of methylene and methyl groups, as shown in Figure 2(b).

The structural changes of the vibration bands of lysozyme induced by the exposure to mobile phone microwaves were studied by FTIR spectroscopy, as well.

When energy is absorbed by an organic system, it is converted in heat causing an increase in dipolar molecules activity and, so, in tissues temperature, altering the biological function. The specific absorption rate (SAR) is a parameter of potential biological significance which is the energy absorbed by the irradiated biological system $(\mathrm{W} / \mathrm{kg})$. The SAR to which the protein was exposed $(0.96 \mathrm{~W} / \mathrm{Kg})$ was lesser than the limits of $1.6 \mathrm{~W} / \mathrm{kg}$ and $2 \mathrm{~W} / \mathrm{kg}$ recommended in the USA and Europe, respectively.

The spectra of the proteins exhibited an intense amide I band centered around $1650 \mathrm{~cm}^{-1}$.

Amide I spectral region of lysozyme acquired after $4 \mathrm{~h}$ of exposure showed a clear increase in intensity in amide I mode after exposure, but not appreciable change was detected in amide II vibration band, as represented in Figure 3 (red dotted lines refer to exposed samples).

Computations of the integrated area of amide I band were conducted for a relevant number of exposed and not exposed samples spectra, showing that the values relative to exposed samples were significantly different in comparison to the controls $(P<0.05)$. 


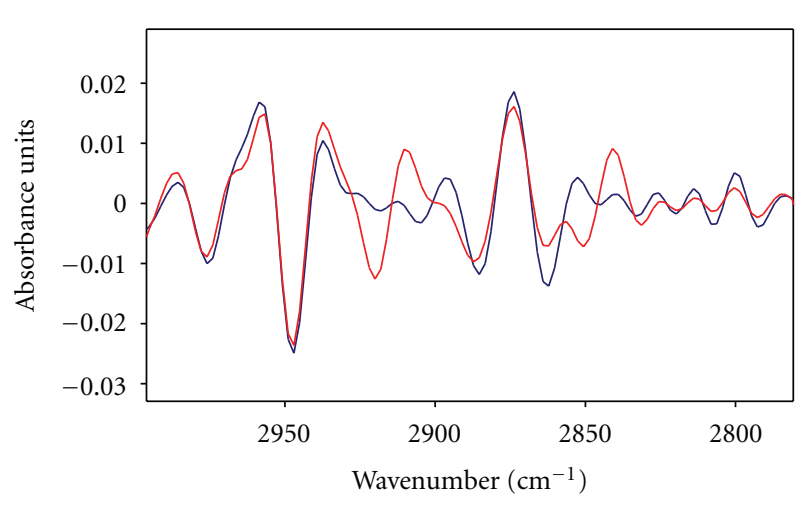

(a)

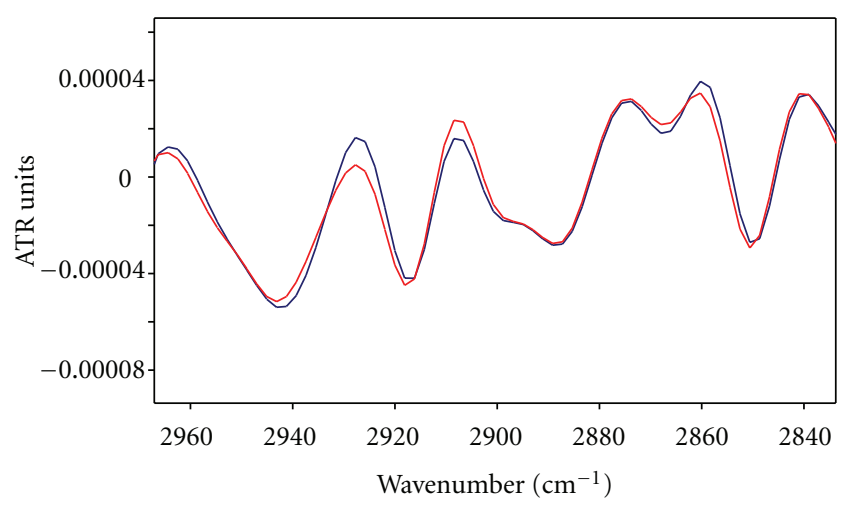

(b)

Figure 2: (a) Second derivative spectra from 3000 to $2800 \mathrm{~cm}^{-1}$ of lysozyme in $\mathrm{D}_{2} \mathrm{O}$ solution. Red line represents the exposed sample spectrum, after $3 \mathrm{~h}$ of exposure to a magnetic field of $180 \mu \mathrm{T}$. The increases of $\mathrm{CH}_{2}$ bands at 2921 and $2853 \mathrm{~cm}^{-1}$ are evidenced. (b) Second-derivative spectra from 3000 to $2800 \mathrm{~cm}^{-1}$ of lysozyme in trehalose $\mathrm{D}_{2} \mathrm{O}$ solution acquired after analogue exposure conditions. No appreciable difference can be observed with respect to not exposed sample's spectrum. Red lines represent exposed sample spectra.

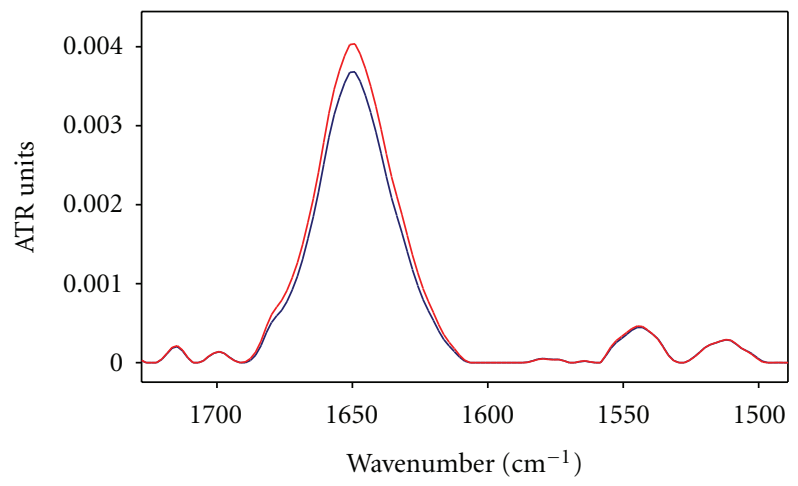

FIGURE 3: Infrared spectrum of amide I and II regions of lysozyme in $\mathrm{D}_{2} \mathrm{O}$ solution acquired after $4 \mathrm{~h}$ of exposure to microwaves at $25 \mathrm{~mA} / \mathrm{m}$ (red-dotted line refers to exposed sample). The increase in intensity of amide I band was evidenced after exposure.

Further manipulations of lysozyme spectra after MW exposure were performed using a spectrum deconvolution.

The concept of Fourier self-deconvolution (FSD) is based on the assumption that a spectrum of single narrow bands is broadened in the liquid or solid state and cannot be distinguished in the amide envelope. A curve fitting procedure can be applied to estimate quantitatively the area of each component representing a type of secondary structure.

In [30] the amide I was deconvoluted with a Lorentzian line shape function and was fitted with Gaussian band shapes by an iterative curve fitting procedure.

FSD analysis was applied to the acquired spectra using a Lorentzian shape, with bandwidth $=18.03$, deconvolution factor $=2$, and noise reduction factor $=0.5$.

A band close to $1650 \mathrm{~cm}^{-1}$ that is due to $\alpha$-helix content, a component around $1635 \mathrm{~cm}^{-1}$ that can be attributed to $\beta$ sheet, structures $[31,32]$, and around $1680 \mathrm{~cm}^{-1}$ which can be associated with $\beta$-turn [33] were revealed.
Significant increases in $\alpha$-helix component, $\beta$-sheet and turn contents of exposed samples spectra resulted, as can be observed, in a typical spectrum represented in Figure 4.

The integrated areas of amide I features were computed for a number of 16 exposed and not exposed samples spectra. The averaged values of the integrated area ratios exposed/unexposed samples of the main conformational components of the amide I band are reported below:

$$
\begin{aligned}
& \alpha \text {-helix (computed from } 1662 \text { to } 1643 \mathrm{~cm}^{-1} \text { ) } \\
& \text { exposed/unexposed }=1.25 \pm 0.05 \text {, } \\
& \beta \text {-sheet (computed from } 1636 \text { to } 1627 \mathrm{~cm}^{-1} \text { ) } \\
& \text { exposed/unexposed }=1.52 \pm 0.25 \text {, } \\
& \beta \text {-turn (computed from } 1685 \text { to } 1675 \mathrm{~cm}^{-1} \text { ) } \\
& \text { exposed/unexposed }=1.70 \pm 0.30 .
\end{aligned}
$$

These values resulted significantly differently in comparison to not exposed samples $(P<0.05)$.

The relevant increase in $\beta$-sheet and turn contents occurred after MW exposure can be attributed to disorder and unfolding processes in the structure of the protein [33-35].

Resonance absorption by lowfrequency vibrations was suggested by $[36,37]$ as a molecular mechanism that would allow non-thermal coupling of MW fields to protein dynamics.

The model of [36] involves the mechanical vibrations of large molecules or components of biological tissue and the way they interact with each other, which he argued could lead to the existence of a band of frequencies into which energy could be absorbed, plus a particular "coherent state" of vibration. [38] suggested that the model proposed by [36] might lead to biological effects from electromagnetic fields at the appreciably lower frequencies of mobile phones.

Our results suggest that further studies would be needed in order to understand the mechanism behind this phenomenon. 


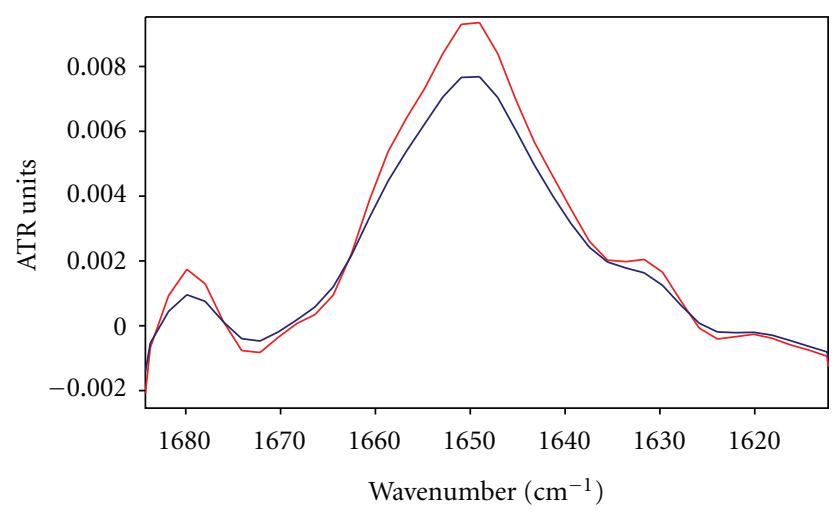

FIgURE 4: A representative Fourier self-deconvolution analysis applied to the spectra of lysozyme in $\mathrm{D}_{2} \mathrm{O}$ solution. A significant increase in intensity of $\alpha$-helix component was observed after $4 \mathrm{~h}$ of exposure (the red lines refer to exposed sample spectra). Increases in $\beta$-sheet and $\beta$-turn structures around 1635 and $1685 \mathrm{~cm}^{-1}$, respectively, (both localized by arrows) were evidenced after the exposure, as well.

\section{Conclusions}

FTIR spectroscopy allowed to characterize the structural properties of lysozyme in $\mathrm{D}_{2} \mathrm{O}$ solution under exposure to EMFs.

The effects of exposure of lysozyme in $\mathrm{D}_{2} \mathrm{O}$ solution (in absence and in presence of trehalose) to an ELF-EMF $(50 \mathrm{~Hz})$ were investigated analyzing the vibration bands of protein linkages in the mid-infrared region. After three hours of exposure at the intensity of $180 \mu \mathrm{T}$ no appreciable alterations were detected in the amide I and II regions. In contrast, relevant changes were observed after exposure in the range from 2800 to $3000 \mathrm{~cm}^{-1}$ represented by an increase in intensity of $\mathrm{CH}_{2}$ group at 1921 and $1853 \mathrm{~cm}^{-1}$ after $3 \mathrm{~h}$ of exposure. The addition of trehalose reduced drastically these effects due to exposure to $50 \mathrm{~Hz}$ EMFs.

The exposure to mobile phone MWs at $900 \mathrm{MHz}$ at the magnetic flux density of $25 \mathrm{~mA} / \mathrm{m}$ of samples of lysozyme in $\mathrm{D}_{2} \mathrm{O}$ solutions produced significant alterations of the protein's secondary structure, evidenced by FTIR spectroscopy, as well.

A significant increase in intensity of the amide I vibration band in the secondary structure of lysozyme was observed after $4 \mathrm{~h}$ of exposure to MWs, confirming a clear change in the protein's conformation. In particular, Fourier self deconvolution spectral analysis of lysozyme in $\mathrm{D}_{2} \mathrm{O}$ solution revealed an increase in intensity of $\beta$-sheet and $\beta$-turn in amide I mode after MW exposure, showing that disorder and unfolding processes in the protein occur due to exposure to MWs.

\section{References}

[1] R. J. Ellis and F. U. Hartl, "Principles of protein folding in the cellular environment," Current Opinion in Structural Biology, vol. 9, no. 1, pp. 102-110, 1999.
[2] M. J. Gething and J. Sambrook, "Protein folding in the cell," Nature, vol. 355, no. 6355, pp. 33-45, 1992.

[3] WHO, "Extremely low frequency (ELF) fields," Environmental Health Criteria 35, World Health Organization, Geneva, Switzerland, 1984.

[4] WHO, "Electromagnetic fields $(300 \mathrm{~Hz}$ to $300 \mathrm{GHz})$," Environmental Health Criteria 137, World Health Organization, Geneva, Switzerland, 1993.

[5] IARC Working Group on the Evaluation of Carcinogenic Risks to Humans, "Non-ionizing radiation, Part 1: static and extremely low-frequency (ELF) electric and magnetic fields," Monographs on the Evaluation of Carcinogenic Risks to Humans 80, IARC, Lyon, France, 2002.

[6] S. Magazù, E. Calabrò, and S. Campo, "FTIR spectroscopy studies on the bioprotective effectiveness of trehalose on human hemoglobin aqueous solutions under $50 \mathrm{~Hz}$ electromagnetic field exposure," Journal of Physical Chemistry B, vol. 114, no. 37, pp. 12144-12149, 2010.

[7] D. M. Byler and H. Susi, "Examination of the secondary structure of proteins by deconvolved FTIR spectra," Biopolymers, vol. 25, no. 3, pp. 469-487, 1986.

[8] W. K. Surewicz and H. H. Mantsch, "New insight into protein secondary structure from resolution-enhanced infrared spectra," Biochimica et Biophysica Acta, vol. 952, no. 2, pp. 115-130, 1988.

[9] K. Fritze, C. Sommer, B. Schmitz et al., "Effect of global system for mobile communication (GSM) microwave exposure on blood-brain barrier permeability in rat," Acta Neuropathologica, vol. 94, no. 5, pp. 465-470, 1997.

[10] F. Tore, P. E. Dulou, E. Haro, B. Veyret, and P. Aubineau, "Twohour exposure to $2 \mathrm{~W} / \mathrm{kg}, 900 \mathrm{MHz}$ GSM microwaves induces plasma protein extravasation in rat brain," in Proceedings of the 5th International Congress of the European Bioelectromagnetics Association, pp. 43-45, Helsinki, Finland, September 2001.

[11] L. G. Salford, A. E. Brun, J. L. Eberhardt, L. Malmgren, and B. R. R. Persson, "Nerve cell damage in mammalian brain after exposure to microwaves from GSM mobile phones," Environmental Health Perspectives, vol. 111, no. 7, pp. 881-883, 2003.

[12] E. Calabrò, S. Condello, M. Currò et al., "Modulation of HSP response in SH-SY5Y cells following exposure to microwaves of a mobile phone," World Journal of Biological Chemistry, vol. 3, no. 2, pp. 34-40, 2012.

[13] E. Calabrò and S. Magazù, "Inspections of mobile phone microwaves effects on proteins secondary structure by means of fourier transform infrared spectroscopy," Journal of Electromagnetic Analysis and Applications, vol. 2, pp. 607-617, 2010.

[14] A. Hédoux, R. Ionov, J. F. Willart et al., "Evidence of a twostage thermal denaturation process in lysozyme: a Raman scattering and differential scanning calorimetry investigation," Journal of Chemical Physics, vol. 124, no. 1, Article ID 014703, 2006.

[15] A. Hédoux, J. F. Willart, L. Paccou et al., "Thermostabilization mechanism of bovine serum albumin by trehalose," Journal of Physical Chemistry B, vol. 113, no. 17, pp. 6119-6126, 2009.

[16] A. Hédoux, J. F. Willart, R. Ionov et al., "Analysis of sugar bioprotective mechanisms on the thermal denaturation of lysozyme from Raman scattering and differential scanning calorimetry investigations," Journal of Physical Chemistry B, vol. 110, no. 45, pp. 22886-22893, 2006.

[17] J. H. Crowe, J. F. Carpenter, and L. M. Crowe, "The role of vitrification in anhydrobiosis," Annual Review of Physiology, vol. 60, pp. 73-103, 1998. 
[18] F. Affouard, P. Bordat, M. Descamps et al., "A combined neutron scattering and simulation study on bioprotectant systems," Chemical Physics, vol. 317, no. 2-3, pp. 258-266, 2005.

[19] S. Magazù, F. Migliardo, and M. T. F. Telling, " $\alpha, \alpha$-Trehalosewater solutions. VIII. Study of the diffusive dynamics of water by high-resolution quasi elastic neutron scattering," Journal of Physical Chemistry B, vol. 110, no. 2, pp. 1020-1025, 2006.

[20] S. Magazù, G. Maisano, P. Migliardo, and V. Villari, "Experimental simulation of macromolecules in trehalose aqueous solutions: a photon correlation spectroscopy study," Journal of Chemical Physics, vol. 111, no. 19, pp. 9086-9092, 1999.

[21] S. Magazù, F. Migliardo, and M. T. F. Telling, " $\alpha, \alpha$-Trehalosewater solutions. VIII. Study of the diffusive dynamics of water by high-resolution quasi elastic neutron scattering," Journal of Physical Chemistry B, vol. 110, no. 2, pp. 1020-1025, 2006.

[22] S. Magazù, F. Migliardo, C. Mondelli, and M. Vadalà, "Correlation between bioprotective effectiveness and dynamic properties of trehalose-water, maltose-water and sucrosewater mixtures," Carbohydrate Research, vol. 340, no. 18, pp. 2796-2801, 2005.

[23] C. Branca, S. Magazù, G. Maisano, and F. Migliardo, "Vibrational and relaxational contributions in disaccharide $/ \mathrm{H}_{2} \mathrm{O}$ glass formers," Physical Review B, vol. 64, no. 22, Article ID 224204, 2001.

[24] A. Dong, P. Huang, and W. S. Caughey, "Protein secondary structures in water from second-derivative amide i infrared spectra," Biochemistry, vol. 29, no. 13, pp. 3303-3308, 1990.

[25] G. Anderle and R. Mendelsohn, "Thermal denaturation of globular proteins. Fourier transform-infrared studies of the amide III spectral region," Biophysical Journal, vol. 52, no. 1, pp. 69-74, 1987.

[26] S. Cai and B. R. Singh, "Identification of $\beta$-turn and random coil amide III infrared bands for secondary structure estimation of proteins," Biophysical Chemistry, vol. 80, no. 1, pp. 720, 1999.

[27] B. Stuart, Biological Applications of Infrared Spectroscopy, vol. 115 of Analytical Chemistry of Open Learning, John Wiley and Sons, Chichester, UK, 1997.

[28] P. Dumas and L. Miller, "The use of synchrotron infrared microspectroscopy in biological and biomedical investigations," Vibrational Spectroscopy, vol. 32, no. 1, pp. 3-21, 2003.

[29] E. Calabrò, S. Condello, S. Magazù, and R. Ientile, "Static and $50 \mathrm{~Hz}$ electromagnetic fields effects on human neuronallike cells vibration bands in mid-infrared region," Journal of Electromagnetic Analysis and Applications, vol. 3, pp. 69-78, 2011.

[30] H. Susi and D. M. Byler, "Resolution-enhanced fourier transform infrared spectroscopy of enzymes," Methods in Enzymology, vol. 130, pp. 290-311, 1986.

[31] A. A. Ismail, H. H. Mantsch, and P. T. T. Wong, "Aggregation of chymotrypsinogen: portrait by infrared spectroscopy," Biochimica et Biophysica Acta, vol. 1121, no. 1-2, pp. 183-188, 1992.

[32] T. Lefèvre and M. Subirade, "Molecular differences in the formation and structure of fine-stranded and particulate $\beta$ lactoglobulin gels," Biopolymers, vol. 54, no. 7, pp. 578-586, 2000.

[33] P. Huang, A. Dong, and W. S. Caughey, "Effects of dimethyl sulfoxide, glycerol, and ethylene glycol on secondary structures of cytochrome $\mathrm{c}$ and lysozyme as observed by infrared spectroscopy," Journal of Pharmaceutical Sciences, vol. 84, no. 4, pp. 387-392, 1995.
[34] R. Bauer, R. Carrotta, C. Rischel, and L. Øgendal, "Characterization and isolation of intermediates in $\beta$-lactoglobulin heat aggregation at high pH," Biophysical Journal, vol. 79, no. 2, pp. 1030-1038, 2000.

[35] S. Magazù, E. Calabrò, and S. Campo, "Studying the electromagnetic-induced changes of the secondary structure of bovine serum albumin and the bioprotective effectiveness of trehalose by ftir spectroscopy," Journal of Physical Chemistry $B$, vol. 115, no. 21, pp. 6818-6826, 2011.

[36] H. Fröhlich, "Long-range coherence and energy storage in biological systems," International Journal of Quantum Chemistry, vol. 2, pp. 641-649, 1968.

[37] J. Pokorny and T. M. Wu, Biophysical Aspects of Coherence and Biological Order, Springer, Prague, Czech Republic, 1998.

[38] G. J. Hyland, "Non-thermal bioeffects induced by low-intensity microwave irradiation of living systems," Engineering Science and Education Journal, vol. 7, no. 6, pp. 261-269, 1998. 


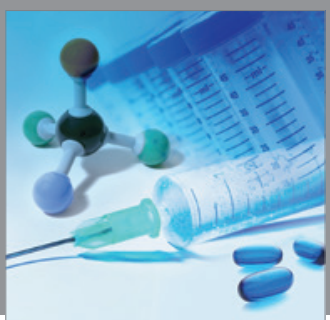

International Journal of

Medicinal Chemistry

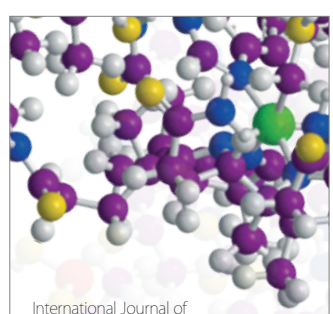

Carbohydrate Chemistry

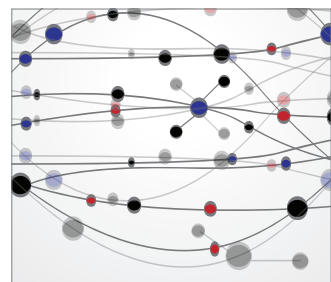

The Scientific World Journal
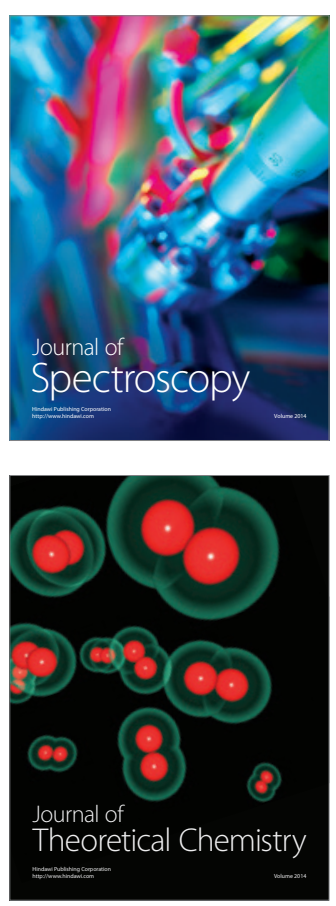
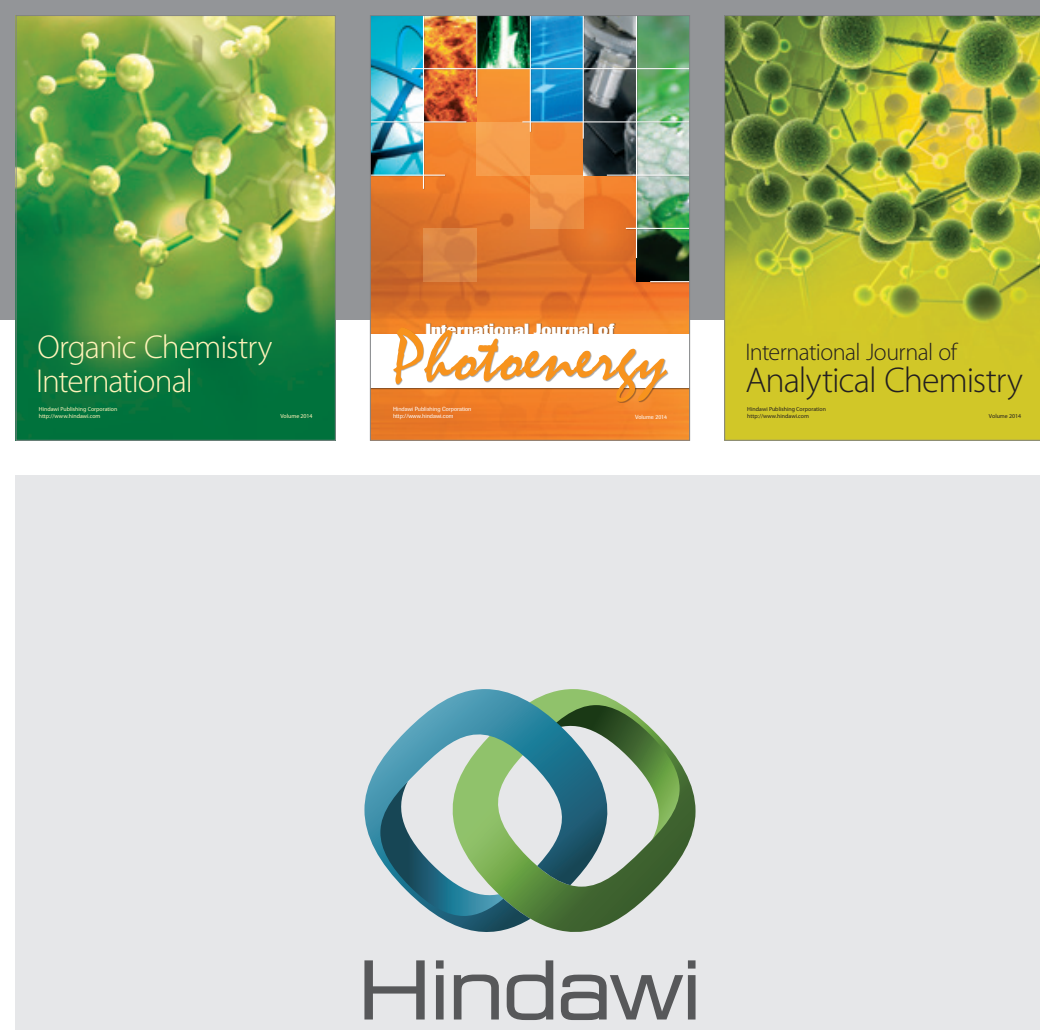

Submit your manuscripts at

http://www.hindawi.com
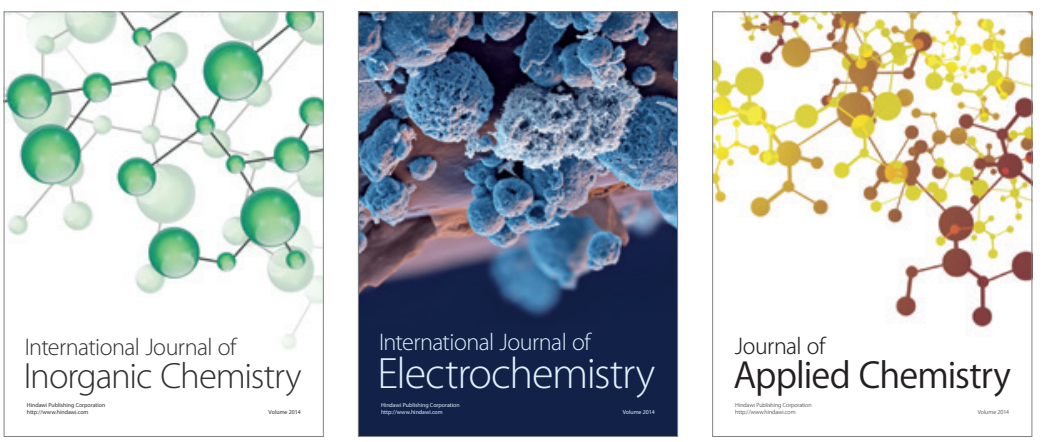

Journal of

Applied Chemistry
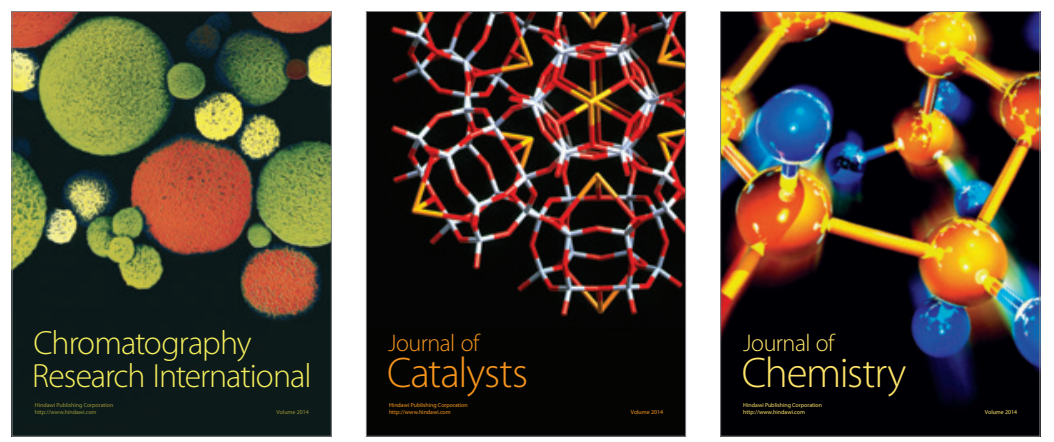
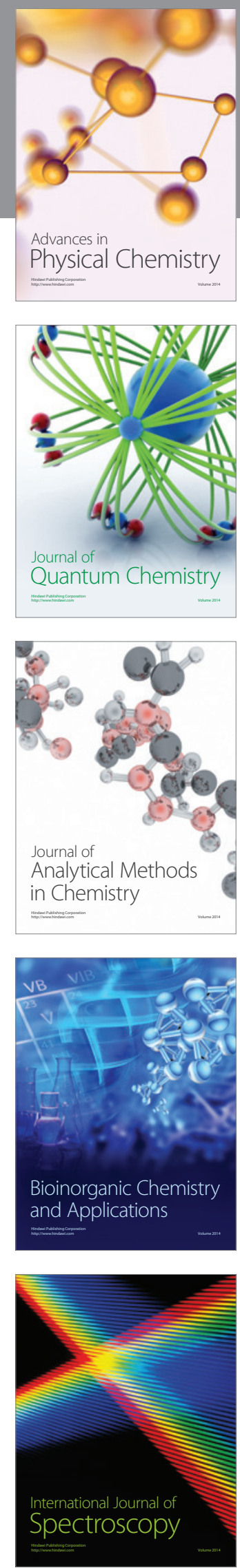